\title{
A pixação enquanto linguagem gráfica: aspectos formais das assinaturas do estilo pixo reto
}

\author{
Pixação as graphic language: the pixo reto style signatures and its formal aspects
}

Ana Kossoski Costa, Isabella Ribeiro Aragão

pixação, pixo reto, assinatura, tipografia, linguagem gráfica

A pixação é uma manifestação visual que apresenta como signo escrito as assinaturas de seus autores, os pixadores. Se o senso comum as percebe como uma "linguagem secreta" e indecifrável, elas são, na verdade, constituídas por codinomes que protegem as identidades oficiais de seus produtores e caracterizadas especialmente pela estilização de suas letras, cuja leitura é compreensível sobretudo pelos seus adeptos e simpatizantes-o que faz com que as assinaturas se comportem como códigos de uma comunicação fechada. A fim de compreender como o referido processo de estilização é realizado a ponto de encerrar em um único padrão estilístico diferentes soluções formais, exemplares do estilo de pixação conhecido como pixo reto, de origem paulista, foram analisados a partir de fotografias que registram as assinaturas em seus contextos originais, resultando uma descrição de seus aspectos.

pixação, pixo reto, signature, typography, graphic language

Pixação is a Brazilian visual manifestation that presents the signatures of its authors, the pixadores, as a written sign. If common sense perceives it as a secret and indecipherable language, it actually consists of code names that protect the official identities of its producers, and is characterized by the stylization of its letters, whose reading is understandable mostly by its followers and supporters-which makes the signatures operate as codes of a closed communication. In order to understand how the aforementioned styling process is carried out, to the point of grouping, in a single stylistic pattern, different formal solutions, examples of the pixação style known as pixo reto were analyzed from photographs that register the signatures in its original contexts, resulting in a description of its aspects.

\section{Introdução}

A pixação é um fenômeno genuinamente brasileiro, presente nas principais metrópoles do nosso país. De potências estéticas, simbólicas e socioculturais, ela pode ser observada sob duas instâncias: ora enquanto prática, isto é, como atividade que se efetiva individual ou coletivamente; ora enquanto artefato comunicativo, ou seja, como manifestação visual que encontra nas assinaturas de seus produtores sua materialização, seu signo escrito. Decerto que ambas as dimensões são interdependentes, considerando-se que o exercício da pixação, marcado pela manualidade, interfere diretamente na aparência das intervenções. Este artigo, no entanto, se concentra sobretudo na segunda abordagem, o aspecto formal das assinaturas,

Anais do $10^{\circ} \mathrm{CIDI}$ e $10^{\circ} \mathrm{CONGIC}$

Kelli C.A.S. Smythe, Rafael de Castro Andrade (orgs.)

Sociedade Brasileira de Design da Informação - SBDI

Curitiba | Brasil | 2021
Proceedings of the $10^{\text {th }} \mathrm{CIDI}$ and $10^{\text {th }} \mathrm{CONGIC}$

Kelli C.A.S. Smythe, Rafael de Castro Andrade (orgs.)

Sociedade Brasileira de Design da Informação - SBDI Curitiba | Brazil | 2021 
com o intuito de descrever algumas das particularidades que singularizam as letras do estilo de pixação conhecido como pixo reto.

Embora na ortografia oficial da língua portuguesa a grafia correta seja com "ch", a decisão por redigir pixação com " $x$ " é pragmática pois nos ajuda a demarcar nosso objeto de estudo, discernindo-a de sua homônima. Segundo Pereira (2010, p. 143), "'pixar' seria diferente de 'pichar', pois este último termo designaria qualquer intervenção escrita na paisagem urbana, enquanto o primeiro remeteria às práticas desses jovens que deixam inscrições grafadas de forma estilizada no espaço urbano". A pixação se distingue da pichação, portanto, por ser resultante da ação sistemática de uma comunidade que se mobiliza em torno da difusão incessante de assinaturas, cujas letras devem ostentar um formato exclusivo.

Assim, ao admitir as assinaturas enquanto linguagem gráfica verbal-visto que elas têm no verbo o seu modo de simbolização, quer dizer, são compostas pelos mesmos caracteres que integram o nosso alfabeto-, buscamos, em um primeiro momento, contextualizá-las a partir do enfoque do design, esclarecendo o motivo delas serem aqui compreendidas enquanto escrita e enquanto código fechado. Logo após, como o movimento da pixação, à nível nacional, abrange mais de um estilo, faz-se necessário um recorte, e por isso o pixo reto, oriundo em São Paulo nos anos 1980, é introduzido, para em seguida ter alguns de seus exemplares comparados e as características que qualificam suas letras enfim especificadas.

Tais exemplares foram documentados através de fotografias, reproduzindo as pixações em seus ambientes originais, em atenção às modificações que podem exibir em cenários distintos. Esses dados imagéticos foram registrados no decorrer de uma pesquisa de campo na cidade de São Paulo, e depois codificados, o que possibilitou reunir mais de uma versão de uma mesma marca. Durante a investigação, a coleta de dados também foi conduzida por meio de outros instrumentos, como as entrevistas e a pesquisa bibliográfica, essenciais para a posterior validação dos resultados a partir da tática de triangulação. O método comparativo para a análise das imagens selecionadas mostrou-se adequado para o cumprimento do objetivo previsto, uma vez que tencionou a verificação de como as mesmas assinaturas são tratadas em diferentes situações, levando-se em consideração as variáveis observadas.

Para a definição das variáveis que nortearam nossa análise, nos apoiamos no sistema de descrição tipográfica formulado por Dixon (2008). De acordo com a autora, "atributos formais são as unidades individuais básicas de descrição que se referem a um tipo de letra e a sua construção" (Dixon, 2008, p. 26, tradução nossa), sendo elas: forma, peso, modulação, proporção, construção, terminais, caracteres-chave e decoração. No presente texto, nos concentraremos principalmente nas categorias proporção e construção.

Ademais, tendo em conta que os atributos formais relatados, ainda que próprios às letras, não pormenorizam a maneira como elas são dispostas em uma composição visual, também nos amparamos na noção de aspecto extrínseco elucidada por Twyman (1982), na medida em que as assinaturas dizem respeito ao arranjo de suas partes, à configuração de um conjunto de caracteres, e por isso têm relação com o espaço entre eles-o espacejamento. 


\section{A pixação enquanto escrita}

Por escrita, adotamos a acepção de Smeijers (2015), posto que este autor recorre à palavra em questão para referir-se à caligrafia, um posicionamento que particularmente nos convêm já que se afasta da ideia de que toda caligrafia deve ser bela, e se aproxima do hábito simples que é escrever à mão. Isso porque, como afirmamos anteriormente, a pixação tem no verbo o seu modo de representação.

Twyman (1982), quem propôs o esquema no qual nos embasamos, que estrutura os tipos de linguagem conciliando os enfoques linguístico e visual, determina ainda uma distinção quanto aos modos de produção da linguagem gráfica, incluindo a verbal, que, segundo ele, pode ser feita à mão ou à máquina. Evidentemente que, por serem autografadas, quer dizer, derivadas do punho de seus respectivos pixadores, as marcas são concebidas manualmente. Entretanto, apenas essa indicação é insuficiente para fundamentar nosso argumento de que a pixação é um modelo de escrita, dado que as letras elaboradas à mão também podem ser classificadas como desenhadas.

Então, conforme Smeijers (2015, p. 19), no que tange à escrita, além do seu modo de produção ser manual, "cada parte significante da letra é feita em um traço". Por esse motivo, ainda segundo o autor, a letra desenhada, também conhecida como letreiramento ou lettering, se discerne da escrita por ter cada parte componente grafada com mais de um traço, o que propicia a "possibilidade muito desejável de reconsiderar e corrigir" (Smeijers, 2015, p. 19).

Nessa perspectiva, um ponto deve ser esclarecido: na pixação, as letras escritas algumas vezes têm seus traços reforçados (figura 1). Isso ocorre por várias razões que podem inclusive ser combinadas: por inexperiência ou por preferência do pixador; pelo instrumento manuseado, por exemplo latas em spray ou rolos de pintura encharcados com látex à base de água, não proporcionar o volume de tinta necessário; pela adrenalina da ação em modalidades mais instáveis; entre outros.

Figura 1: Falhas ou reforço no traçado da pixação.
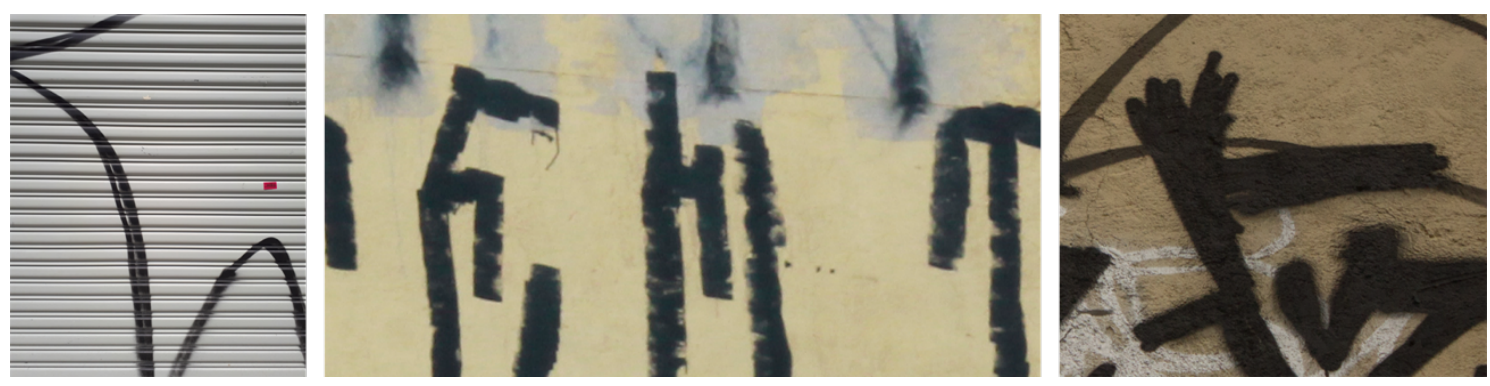

Mas o fato disso acontecer não significa que as letras escritas, quando corrigidas, recebem um aprimoramento equivalente ao tratamento estético que as desenhadas costumam ostentar. Isso é perceptível no grapixo (figura 2), que incorpora o graffiti ao pixo reto, empregando cores e técnicas típicas do primeiro e preservando a identidade do segundo. As assinaturas deste estilo, em vez de terem os elementos que constituem seus caracteres elaborados a partir de 
um único traço, são aos poucos construídas (primeiro é feito o preenchimento para depois o contorno de cada letra ser demarcado), e por isso se aproximam, no nosso ponto de vista, do desenho e, consequentemente, do letreiramento.

Figura 2: Grapixo.
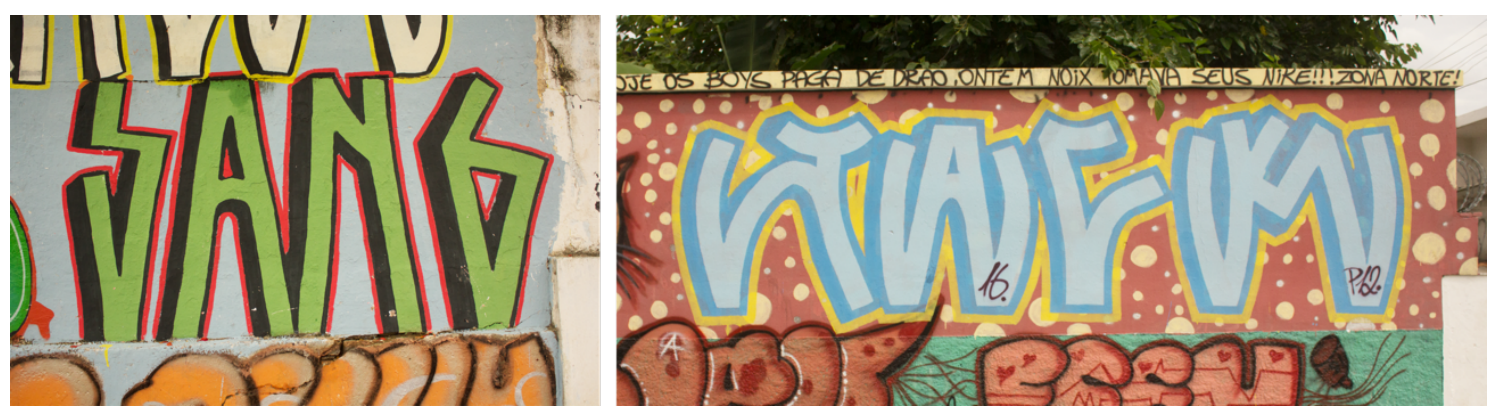

Assim, no caso da pixação, entendemos que o que difere as letras escritas das desenhadas não é exatamente a manualidade de seus processos ou a qualidade de poderem ser corrigidas ou não, mas a quantidade de linhas tracejadas para gerar o que Smeijers (2015) denomina de "parte significante" da letra. Nesse sentido, com exceção do grapixo, todos os outros estilos até então consagrados—o pixo reto, o xarpi e seus hibridismos-, podem ser considerados escritas pois suas letras são, via de regra, produzidas por um só traço.

Outro fator que vale ser mencionado é o tempo dedicado para a execução das inscrições. Por ser uma atividade ilegal, a velocidade é uma condição que na maioria das vezes orienta o "rolê", exercício que efetiva a prática da pixação na rua e comporta adversidades. Dependendo da modalidade elegida ou da localidade intervista, os pixadores se submetem a posições e/ou situações arriscadas, de tal modo que as intervenções geralmente precisam ser concluídas em um curto intervalo de tempo.

Não obstante, devemos ter em mente que entre seus praticantes as assinaturas são feitas para serem admiradas, contempladas, e por isso executá-las com relativa qualidade, ainda que rapidamente, é tão determinante quanto a originalidade de suas formas-quando se trata de obter prestígio entre seus pares. Afinal, um dos preceitos que rege a pixação desde o seu princípio é a visibilidade:

Os pixadores perceberam que o espaço urbano poderia ser utilizado como uma forma de mídia e começaram a fazer propaganda de si mesmos, processo este que resultou em uma competição cada vez mais acirrada na qual a busca por visibilidade fez surgir uma cultura específica, com códigos, valores e critérios de avaliação particulares (Pennachin, 2012, p. 237).

Considerando-se que quando a pixação surgiu, nos anos 1980, os meios de comunicação, sobretudo os impressos, eram protagonistas, a repercussão midiática sobre o movimento que recém se instaurara conferiu às marcas que apareciam ao longo da paisagem citadina um sentido de autoria, de assinatura-embora fossem anônimas. Tal façanha, que ainda na atualidade pondera visibilidade e invisibilidade, reconhecimento e anonimato, só é possível mediante uma operação de codificação. 


\section{A assinatura enquanto código fechado}

Como sabemos, na pixação a assinatura é a combinação de um codinome e de um aspecto formal exclusivo, e pode remeter à um único indivíduo ou então à um grupo. Do inglês code name, o codinome nada mais é que uma designação adotada para esconder a identidade oficial de seu(s) produtor(es). Seu conteúdo não precisa ser necessariamente um apelido ou pseudônimo. Alguns pixadores, por exemplo, definem suas assinaturas a partir dos caracteres que as compõem, indicando certa predileção por determinado sinal gráfico.

Em um cenário marcado pelo controle e vigilância da população, uma das estratégias para escaparem de uma eventual perseguição e possível punição é a manutenção do anonimato, já que praticam atos considerados ilícitos:

[...] o sujeito que as instala quer não ser visto, pois pode ser punido por seu ato e não conta com a sanção positiva da sociedade [...]; porém, ao instalar a sua marca, quer ser visto "em representação", revestido de sua identidade de interventor, que é exibida ao público por meio do codinome e do arranjo estético da assinatura (Altamirano, 2018, p. 154).

Ou seja, apesar de permanecerem desconhecidas aos olhos do cidadão comum e seus autores "invisíveis" perante à sociedade, as assinaturas são apreendidas pelos integrantes do circuito da pixação pois representam uma forma codificada de identificação. Por isso seus aspectos formais são tão criteriosamente desenvolvidos e cuidadosamente replicados-até porque um semblante diferenciado pode ser decisivo não apenas para o seu reconhecimento, mas, antes, para a sua visualização dentre as demais informações que saturam o ambiente urbano e com as quais compete. Além disso, as reuniões nos "points" são oportunas pois permitem que as pessoas envolvidas no movimento se conheçam e associem as inscrições que reparam pela cidade aos seus respectivos autores, mesmo quando suas aparências são avaliadas como sendo extremamente rebuscadas inclusive pelos próprios pixadores.

A pixação se estabelece, portanto, como uma comunicação fechada, resultante de um processo de identificação coletiva no qual as assinaturas comportam-se como códigos dominados somente pelos seus adeptos, quando muito pelos seus simpatizantes. Como coloca Pereira (2016, p. 90), "a sua grande transgressão está em criar um outro regime de visibilidade que não faz sentido para todos, mas apenas para um grupo restrito". Dessa maneira, além de compartilharem um mesmo repertório cultural, os pixadores fazem uso de uma linguagem gráfica particular porque nela reconhecem suas estruturas, estilos e demais procedimentos para a sua produção.

\section{Contextualização da pixação paulista}

De acordo com Altamirano (2018, p. 158), "em meados da década de 1980, algumas pichações (ainda aqui grafadas com 'ch') [...] passam a ser vistas com grande frequência nas áreas públicas da cidade de São Paulo, exibindo sempre os mesmos nomes e formato individual de letras". Note que o emprego do termo com "ch" e a sua ênfase é relevante pois, como nós, a 
autora decide discriminar fenômenos figurativamente distintos a partir da grafia. Isto posto, ela defende que, embora os produtores dessas pichações já adotassem alguns procedimentos típicos da pixação na sua generalidade, como espalhar assiduamente a mesma marca em locais que the propiciem visibilidade, elas não apresentavam um padrão estético específico e por isso não podem ser decretadas pixações. Entendemos que o desenvolvimento de um padrão estético específico—neste caso o estilo pixo reto-foi essencial para a consolidação da pixação paulista como é percebida nos dias atuais, mas ainda que não tivessem avançado formalmente, as repercussões que essas primeiras inscrições suscitaram foram cruciais para a inauguração da pixação.

Consideramos, então, que o pioneiro em São Paulo foi JUNECA (figura 3), que começou a pixar no início de 1980 (Lassala, 2014). Com seus parceiros PESSOINHA e BILÃO, preenchia a capital por regiões, até que a repetição de seus codinomes foi constatada pela imprensa local na segunda metade da década, conforme noticiado, por exemplo, pelo jornal Folha de São Paulo em 4 de janeiro de 1987 (André, 1987), e também pelas autoridades públicas. Para Lara (1996), a perseguição que esses rapazes sofreram durante o mandato de Jânio Quadros fez com que ganhassem fama, promovendo a pixação como uma maneira "do jovem excluído da sociedade ganhar uma rápida notoriedade" (Lara, 1996, p. 123). Em outras palavras, a superexposição do assunto na mídia e a repressão reforçaram a imagem ousada que se desejava combater, fomentando a adesão de novos membros ao coletivo que se estabelecia. Uma matéria publicada em 24 de novembro de 1989 no jornal Estado de São Paulo confirma como naquele ano o movimento da pixação já se encontrava instituído, não mais sendo "uma ação desorganizada de indivíduos isolados" (Vallerio \& Dias, 1989, p. 32).

Figura 3: JUNECA e PESSOINHA (usado com a permissão de Juneca/Beside Colors).
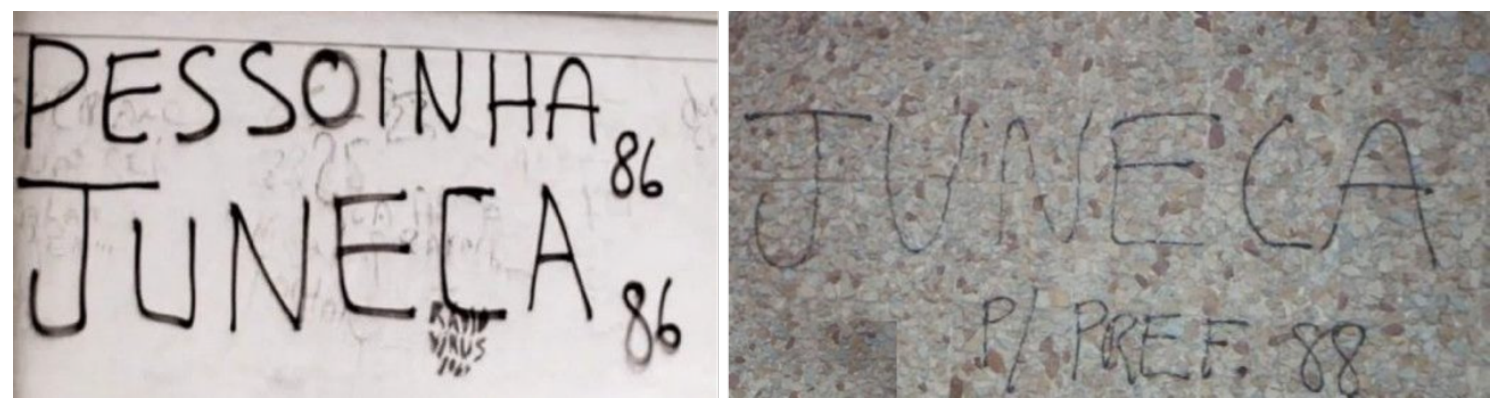

\section{A origem do pixo reto}

Em relação ao aspecto formal das assinaturas, não encontramos nenhuma referência que indique com precisão o momento em que a pixação paulista recebeu o formato vertical e anguloso que a caracteriza na atualidade. Como vimos, seus primeiros exemplares eram aparentemente simples e reproduziam os caracteres maiúsculos do nosso alfabeto sem estilizá-los. A única informação que sugere a recorrência de um padrão estilístico é uma reportagem publicada no jornal Folha de São Paulo, datada de 6 de março de 1989, que diz: "os novos pichadores da cidade adotaram recentemente letras que lembram motivos góticos e 
gregos" (Tognolli, 1989, p. 1). Apesar dessa inexatidão temporal, é possível afirmar, com base nas imagens abaixo (figura 4), que no final dos anos 1980 e início dos 1990 já havia indícios de uma preocupação estética por parte dos pixadores.

Figura 4: Escadaria do MASP em 1989 e Edifício Itália em 1991, na capital paulista (usado com as permissões de Paulo Cerciari/Estadão Conteúdo e de Heitor Hui/Estadão Conteúdo).
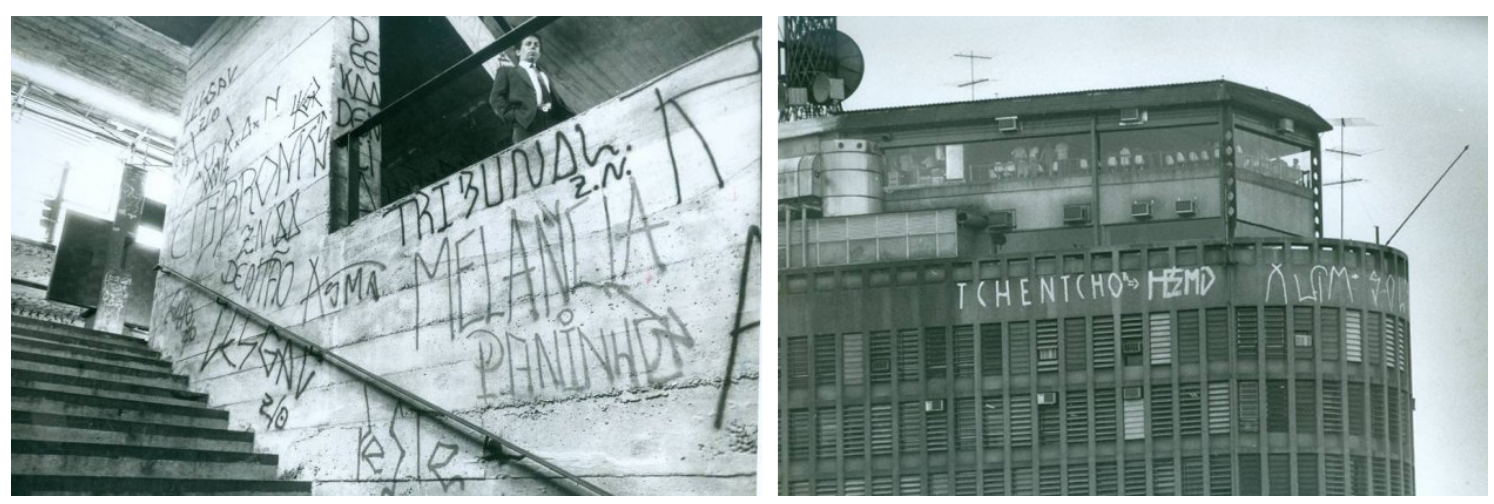

Segundo Chastanet (2007), em um contexto visualmente saturado, já que o circuito da pixação ganhara força e novos integrantes, alguns pixadores, a fim de distinguirem as suas assinaturas das demais, passaram a incorporar diferentes atributos das escritas gótica, rúnica e etrusca às suas letras (figura 5). Isso ocorreu em virtude da influência de algumas vertentes musicais populares na época, como o rock e o heavy metal; bandas desses gêneros eram idolatradas pelos pixadores e, por esse motivo, eles se inspiraram nas capas de seus discos, que traziam versões modernas e simplificadas dessas escritas. Além disso, "o recurso de 'capitalização' também foi reforçado pela influência dos logotipos, quase que exclusivamente imaginados em maiúsculas" (Chastanet, 2007, p. 248, tradução nossa).

Figura 5: Influência das escritas gótica, rúnica e etrusca no pixo reto. O autor da imagem optou pela representação da escrita gótica a partir do estilo conhecido por fratura (primeira linha do primeiro grupo), além de ter espelhado as letras etruscas (primeira linha do terceiro grupo), que eram tradicionalmente lidas da direita para a esquerda (usado com a permissão de François Chastanet).

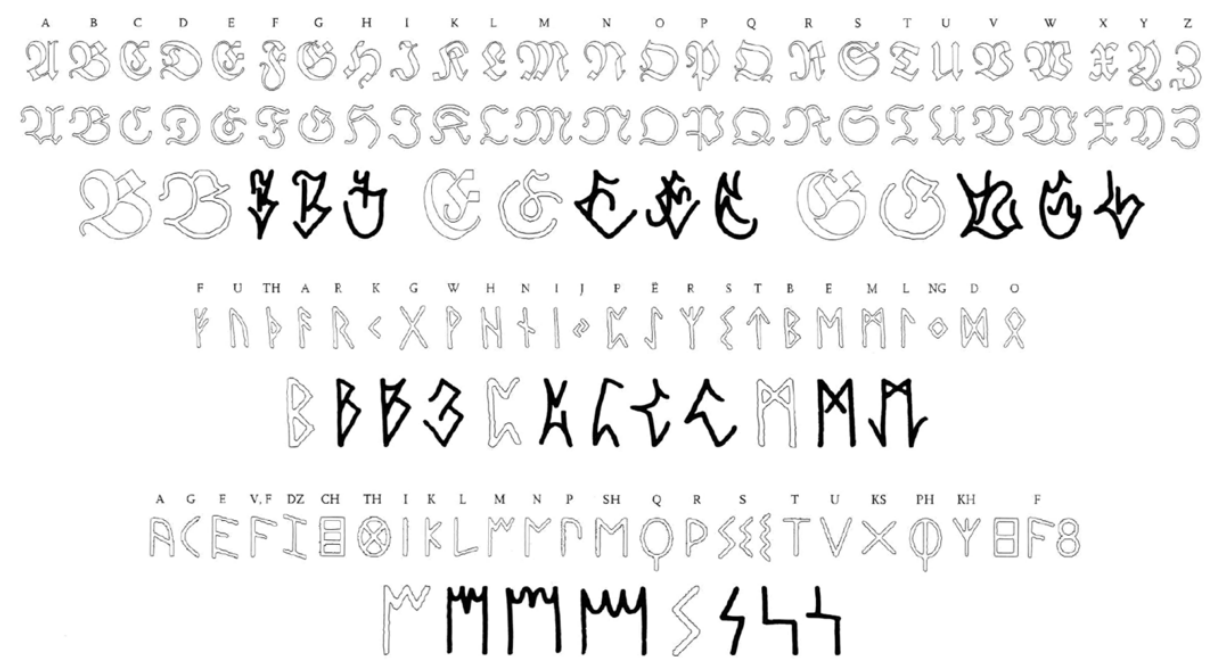




\section{A letra do pixo reto}

O pixo reto existe há mais de três décadas, e por isso provavelmente as novas gerações replicam fórmulas cristalizadas. Vimos que, na sua origem, os primeiros pixadores se inspiraram nos logotipos de bandas. Retomando esta última conjuntura:

A reprodução e adaptação desses logos tipográficos usando ferramentas do cotidiano, como a caneta esferográfica ou de ponta de feltro no papel e com um rolo de tinta ou spray na parede [...], aparece principalmente como linhas monolineares (Chastanet, 2007, p. 247, tradução nossa).

Isso significa que, desde os seus primórdios, as letras do pixo reto apresentam uma espessura monolinear, cuja largura é determinada pelo instrumento operado. Tendo em vista que as assinaturas devem ostentar um aspecto original, essa estética reforça o seu caráter caligráfico, já que um conjunto de traços é suficiente para a geração de diferentes soluções (figura 6), e viabiliza a manutenção dos atributos formais-sejam as inscrições feitas com o rolo de pintura ou com o spray. Em suma, a redução das formas a "linhas monolineares", descrição propositalmente redundante, possibilita a preservação dos elementos estilísticos das letras, bem como uma adequação instrumental.

Figura 6: O traçado do pixo reto é monolinear.
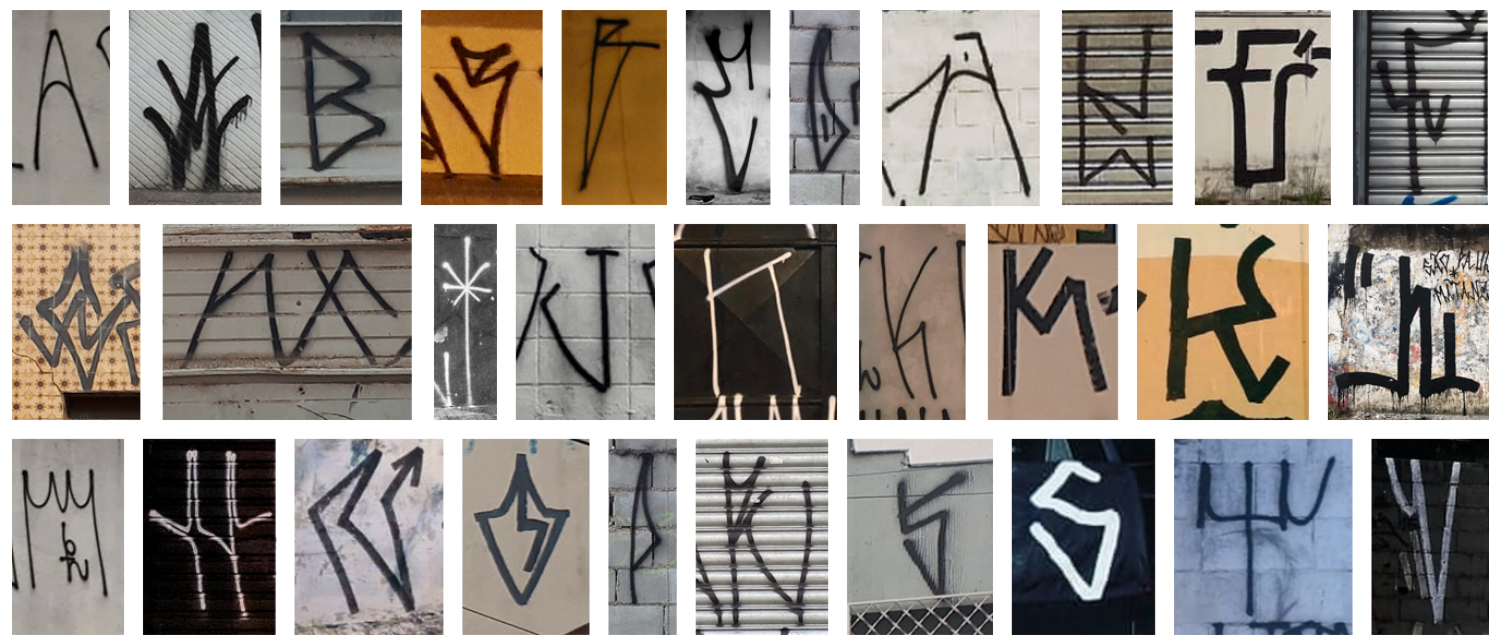

Para Chastanet (2007, p. 247, tradução nossa), isso é resultado de "uma noção gráfica de economia de recursos", relativa aos materiais e aos movimentos gestuais empregados, que obedecem "à lei do menor esforço (ou 'linha de menor resistência')" (Chastanet, 2007, p. 248, tradução nossa). Em um cenário ideal, a lei do menor esforço demanda que os materiais sejam leves, funcionais e operacionais. Já no caso dos movimentos gestuais, sintetizar as formas das letras em linhas, mais que ser esteticamente ou instrumentalmente útil, é um procedimento fácil de ser implementado, principalmente considerando-se a circunstância do ato contraventor, que requer agilidade por parte dos interventores. A sua economia, deliberada ou não, ocasiona o traçado monolinear do pixo reto. 
Ao mesmo tempo, se, por um lado, priorizar poucos traços ou traços mais simples propicia uma fluência da escrita, favorecendo o movimento gestual, por outro, o paradigma monolinear entrava os movimentos gestuais associados aos traços curvilíneos, revelando-se, em algumas situações, rígido e limitado-sobretudo quando o "rolinho" é manipulado. A consequência disso é a predominância de traços retos, que dão nome ao estilo de pixação oriundo em São Paulo.

O contraste é a diferença entre os traços grossos e os traços finos. No pixo reto, embora as letras sejam monolineares, algumas vezes aparentam certo contraste devido ao modo como o instrumento foi manuseado-o que significa que a qualidade do traço e, por conseguinte, a aparência da letra pode variar. Tal contraste costuma ser mais evidente nos seus pontos de transição ou nas suas extremidades.

No pixo reto, se o instrumento manipulado for o spray, algumas letras podem ser construídas de maneira contínua, sem que a tinta deixe, em algum momento, de ser sobreposta na superfície parietal intervista, escrevendo-se a totalidade de suas partes componentes com um único traço, até sua forma ser completamente finalizada. Não obstante, a construção, de modo geral, é interrompida, já que permite que as partes significantes sejam traçadas a partir de qualquer ponto ou segmento.

O estudo antecipado do local enquanto estratégia de intervenção tem como uma de suas vantagens a previsão do arranjo da assinatura na área demarcada. Considerando que cada localidade demanda uma estratégia específica, muitas vezes não é possível sobrescrever as letras em uma ordem linear, ou melhor, em uma ordem cronológica:

Essa escrita não é concebida para atender aos requerimentos do papel e da mão, mas em respeito aos movimentos factíveis do corpo, isso implicando em uma simplificação e segmentação do leiaute, a fim de garantir a possibilidade subsequente de desenhar a letra, então a palavra-imagem, em vários movimentos separados (Chastanet, 2007, p. 239, tradução nossa).

Ou seja, o pixador, familiarizado com a sua assinatura, normalmente já tem os movimentos gestuais, correspondentes à cada parte significante das letras, operacionalizados. Por sua vez, a fragmentação de suas formas atesta que a construção é interrompida e sugestiona que há um número de traços, bem como uma dada ordem e sentido para a sua execução-um ductus $^{1}$. No entanto, o que se percebe na pixação paulista é que tal ordem e sentido préestabelecidos não precisam ser obedecidos à risca. Embora o formato final da assinatura concentre uma combinação singular de traços, pode derivar de diversos caminhos.

As amostras de FURTOS da figura 7 são certamente monolineares, mas na imagem esquerda aparentam ser mais contrastantes na base em virtude da angulação com a qual o spray foi comprimido. Os elementos estilísticos são conservados pois, afinal, trata-se da mesma assinatura. Contudo, o que é interessante observar nesses exemplos é como as letras são redimensionadas. Na imagem esquerda a área livre para a composição é maior, enquanto na direita é menor. O espacejamento entre elas também é oposto, ou seja, na primeira situação é generoso, folgado, ao passo em que na segunda é parco, apertado.

\footnotetext{
${ }^{1} \mathrm{O}$ ductus corresponde à uma dada quantidade de traços e a ordem e orientação em que são traçados.
} 
Figura 7: FURTOS na modalidade pico e chão.
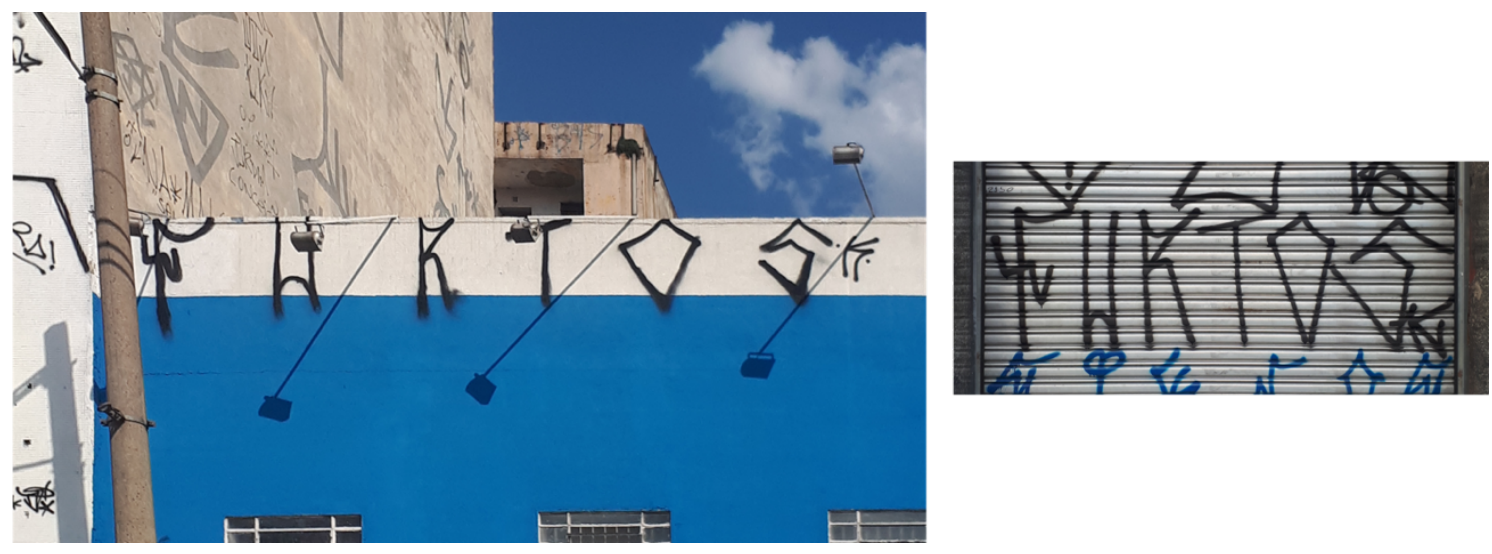

Abstraindo momentaneamente a questão do espacejamento, o que também se verifica é que a proporção entre as letras-a relação entre a altura e a largura-apresenta disparidades. No que diz respeito à largura, os caracteres da imagem esquerda parecem ser expandidos quando comparados aos da direita, condensados. Essa variação acontece com frequência na pixação paulista porque o tamanho da assinatura não só é adaptado ao local intervisto, como é delegado ao pixador.

Sabemos que na escrita formal, a medida da altura das letras de determinado estilo caligráfico geralmente é dada por uma quantidade de "larguras da ponta" da caneta, e que a proporcionalidade entre a altura e a largura é assegurada pela forma essencial e suas partes características (Johnston, 1906). Nos softwares de edição, o tamanho do corpo é definido pelo designer, porém a largura da face tipográfica é inerente à fonte com que se trabalha. No pixo reto, o tamanho das letras é responsabilidade do pixador. Embora o ideal seja ajustar a largura à altura, ou o contrário, a favor da uniformidade do conjunto, é comum privilegiar-se uma em detrimento da outra para que a assinatura ocupe o espaço disponível na sua totalidade.

Além disso, com exceção das vezes em que recursos de longo alcance, como um cabo anexado ao "rolinho", são utilizados, o tamanho das letras é limitado pela extensão corporal de seu autor, ou seja, o ponto máximo que a altura e a largura atingem corresponde ao movimento mais extremo que ele pode realizar.

Nesse sentido, o espacejamento tem papel significativo na decisão do pixador, mais se sua assinatura for extensa. Ainda que alguns interventores, a fim de evitar a distorção das formas das letras, ultrapassem o limite-físico ou imaginário-do suporte, muitas vezes exceder tal barreira pode não ser viável ou desejável. Adequar o espaço entre elas à superfície elegida é uma alternativa coerente e recorrente.

Entretanto, se o espacejamento oportuniza a concretização da marca, também pode afetar sua proporção. Na figura 8 o tratamento atribuído ao espaço, visivelmente apertado, será aqui considerado invariável, idêntico em ambos os cenários. Na primeira imagem, OSCURURU preenche uma área cuja dimensão sinaliza o tamanho que as letras corporificam: a altura é demarcada pelo intervalo entre as janelas, enquanto a largura de cada caractere parece ter sido previamente estipulada para acomodar a assinatura integralmente. O resultado é 
homogêneo, respeitando-se a proporção-afora o último $U$, que provavelmente fora expandido para completar o vazio ao final. Já na segunda imagem, a dimensão da área intervista é menor. Enquanto a altura se eleva até o suporte externo do andar superior, mostrando-se um pouco maior, mais vertical em comparação à primeira, a largura aparece mais condensada-vide a base do R. Mesmo controlando-se o seu tamanho, bem como o seu espacejamento, as letras avançam as paredes laterais. Claro, elas poderiam ter sido feitas encurtadas, porém uma das motivações que move o pixador é ter sua assinatura visualizada, e talvez por isso privilegiou-se a altura.

Figura 8: OSCURURU na modalidade janela.
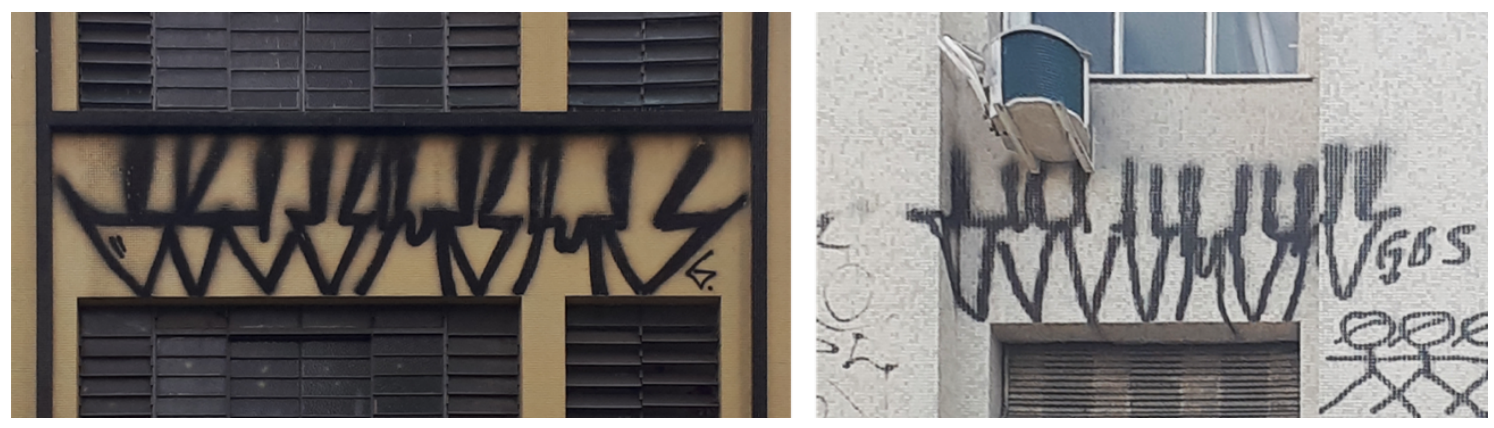

Esses exemplos, na verdade, pouco dizem sobre a relação entre o espacejamento e a proporção, mas elucidam a importância da dimensão, um fator anterior à resolução do tamanho e do espaço entre as letras, incontrolável e primordial, que dita como a assinatura poderá ser disposta. Se acaso ela for ampla, espaçosa, o pixador tem maior liberdade criativa, mas se for pequena, suas opções são reduzidas, e a tendência é que a altura seja verticalizada e a largura condensada.

Na figura 9, em vez de ser impreterível, o espacejamento apertado é agenciado por OSCURURU (segunda pixação de cima para baixo) em prol da estética: suas letras foram exageradamente alargadas ao longo do comprimento da área intervista. Ao que parece, se mais uma vez a altura foi estremada pela dimensão do suporte, a disponibilidade de uma extensão considerável para a inscrição estimulou seu autor a trabalhar a largura de suas formas, expandindo-as e arranjando-as próximas umas das outras para ganhar ainda mais espaço. O espacejamento foi, neste caso, intencionalmente apertado—não obstante, quando comparado aos exemplares da figura 8 , ele parece normal. 
Figura 9: OSCURURU na modalidade escalada.

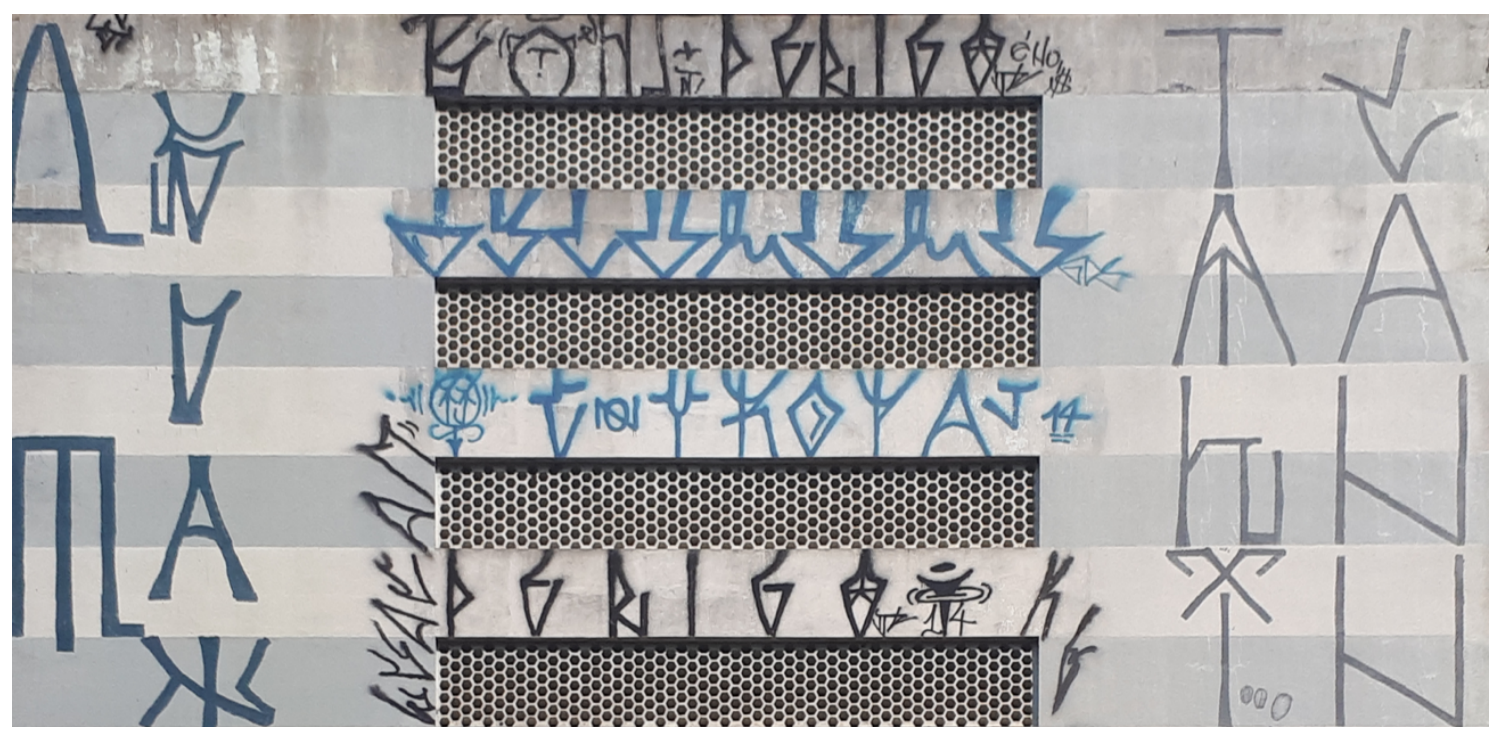

Temos então que, de modo geral, no pixo reto, a altura, a largura e o espacejamento são interdependentes, determinadas pelo suporte citadino e pela extensão corporal do pixador. $\mathrm{O}$ tamanho da letra varia conforme a dimensão do suporte e o alcance do interventor, e o espaço entre os caracteres, seja ele folgado, normal ou apertado, interfere suas formas. Logo, a proporção é condicional a todos esses aspectos, subordinada à conjuntura mesmo que sua consistência constitua um preceito.

Todavia, além dessa correlação consistir em uma frágil tentativa de encerrar a pixação em uma teoria, ela somente é aparente mediante uma comparação isolada. A paisagem citadina, visualmente saturada em múltiplas camadas, introduz outras informações como a hierarquia, a escala, o enquadramento etc. Ademais, os pixadores, baseando-se nas características de suas respectivas assinaturas, trabalham esses parâmetros até romperem com os limites relativos à legibilidade, o que oportuniza a singularidade de cada uma de suas réplicas multiplicadas pelas superfícies urbanas, e a criação e ampliação de um espectro formal que se assemelha às famílias tipográficas.

\section{Considerações finais}

Em síntese, além de ser um tipo de escrita por ser resultante de movimentos gestuais e corporais, no qual cada parte componente das letras é geralmente concebida em um único traço, o pixo reto lança mão de elementos compositivos tipográficos. Em outras palavras, a preocupação estética de seus produtores se alicerça em critérios de composição similares àqueles aplicados na tipografia, estabelecendo uma relação de proximidade entre a pixação paulista e o design, ao passo em que ambas são práticas criativas e processuais.

Especificamente no âmbito do design da informação, contextualizar e esclarecer a forma das letras na sociedade é pertinente pois expande suas questões teóricas. 


\section{Referências}

Altamirano, M. (2018). A pixação na paisagem de São Paulo: o risco como construção do sentido da vida urbana [Dissertação de mestrado]. Departamento de Comunicação e Semiótica. Pontifícia Universidade Católica de São Paulo, São Paulo.

André, B. (1987). 'Graffiti' tentam recuperar criatividade nas pichações. Folha de São Paulo, São Paulo, 04 jan., Seção A, Caderno 2, Cidades, 18.

Chastanet, F. (2007). Pixação: São Paulo signature. Toulouse: XGpress.

Dixon, C. (2008). Describing typeforms: a designer's response. InfoDesign, 5(2), 21-35. https://doi.org/10.51358/id.v5i2.53

Johnston, E. (1906). Writing, illuminating and lettering. London: John Hogg.

Lassala, G. (2014). Em nome do pixo: a experiência social e estética do pixador e artista Djan Ivson [Tese de doutorado]. Departamento de Arquitetura e Urbanismo. Universidade Presbiteriana Mackenzie, São Paulo.

Lara, A. H. (1996). Grafite: arte urbana em movimento [Dissertação de mestrado]. Escola de Comunicações e Artes. Universidade de São Paulo, São Paulo.

Pennachin, D. L. (2012). Subterrâneos e superficies da arte urbana: uma imersão no universo de sentidos do graffiti e da pixação da cidade de São Paulo [Tese de doutorado]. Escola de Belas Artes. Universidade Federal de Minas Gerais, Belo Horizonte.

Pereira, A. B. (2018). Um rolê pela cidade de riscos: leituras da pixação em São Paulo. São Carlos: EdUFSCar.

Pereira, A. B. (2010). As marcas da cidade: a dinâmica da pixação em São Paulo. Lua Nova, 78, 143-162. http://doi.org/10.1590/S0102-64452010000100007

Smeijers, F. (2015). Fatores fundamentais. In Smeijers, F. Contrapução: fabricando tipos no século dezesseis, projetando tipos hoje (pp. 11-39). Brasília: Estereográfica.

Tognolli, C. J. (1989). Pichadores poluem a paisagem e ainda dizem que há muita sujeira. Folha de São Paulo, São Paulo, 06 mar., Seção C, Caderno Cidades, 1.

Twyman, M. (1982). The graphic representation of language. Information Design Journal, 3(1), 2-22. https://doi.org/10.1075/idj.3.1.01twy

Vallerio, C. \& Dias, B. M. (1989). Rabiscos que infernizam a vida da cidade. Estado de São Paulo, São Paulo, 24 nov., 32.

Ana Kossoski Costa, mestranda, UFPE, Brasil <anakossoski@gmail.com> Isabella Ribeiro Aragão, Dra., UFPE, Brasil <isabella.aragao@ufpe.br> 